International Journal of Management Science and

Business Administration

Volume 2, Issue 12, November 2016, Pages 7-19

DOI: $10.18775 /$ ijmsba.1849-5664-5419.2014.212.1001

URL: http://dx.doi.org/10.18775/ijmsba.1849-5664-5419.2014.212.1001

\title{
An Overview of Demand Management through Demand Supply Chain in Fashion Industry
}

Shahriare Mahmood, Pekka Kess

Department of Industrial Engineering and Management, University of Oulu, Finland

\begin{abstract}
Accomplishing veritable demand in a timely manner is a true challenge in present business circumstances especially for the fashion products where the demand is to get more varieties in short interval. Managing demand and supply is not that naïve as the supply chain is complicated by the outsourcing trend. This study aims to assess how brands in the fashion industry are managing their demand-supply chains (DSCs) by considering both trendy and regular product. This paper is based on the literature review of demand chain management (DCM) and also supply chain management (SCM) of the fashion industry. Also the research on demand-supply chain management (DSCM) is studied as a scope of demand-supply management in fashion industry. Textile and apparel processing stages are also studied to understand the manufacturing and supply chain complexity. The review identified that the degree of fashion sensitivity adopted by the retail brands influences their supply chain strategy. Fast fashion retailers urge to respond quickly and they need a flexible and responsive supply chain and contrariwise, others do need fast response but more efficiency focus with economy of scale. This study focuses on the DSCs of the brands which have ample information in journal articles, associated companies' web sites, and other web resources. The demand side aspects and supply side alignment will contribute insights on DSC organization in textile-apparel supply chain. Also textile and apparel manufacturers may have a clearer picture regarding the structure of retailers' DSCs. The findings may also prove useful for them who are not aligned with the fast track concept, but yet supplying product in timely manner is their top priority. The co-ordination of complex and multidimensional textile-apparel supply chain with individual interest is still a concern and yet to be resolved. The objective of the study is to add knowledge for perceiving the importance of the co-ordination for mutual benefit.
\end{abstract}

Keywords: Chinese engineering and business schools, Regionalization, Globalization, Research approach, Kant, Chaos theory

\section{Introduction}

The fashion industry has seen significant transformation in recent past. The rise of globalization trend in last few decades redefined the production strategy where outsourcing prevalent among many top brands. In order to remain competitive, many corporations feel they must send some of their jobs offshore because their competitors have already done so (Shelton \& Wachter, 2005). Price combat among the brands urges for offshore production, on the other hand, product variety and quick replenishment complicates the manufacturing and distribution, because fashion industry is predominantly dealing with the products which are characterized by short product life cycles, volatile and unpredictable demand, tremendous product variety, long and inflexible supply processes, and a complex supply chain (Sen, 2008). Moreover, the evolvement of fast fashion brought new consumer groups and also enhanced the consumption by the existing groups. The consumer taste has changed over time, and the tendency is more varieties in short period. Since the 1980s, a typical life cycle for fashion apparel had four stages: introduction and adoption by fashion leaders; growth and increase in public acceptance; mass conformity (maturation); and finally the decline and obsolescence of fashion (Bhardwaj \& Fairhurst, 2010). The impact of the change is multidimensional, and its influence on the business is big. The supply chain is lingered and span is widened because of outsource potential from many sources. 
The complexity and the span of the fashion supply chain draws attention of the academicians and practitioners which results many studies on the supply and demand management. According to Canever et al. (2008), the increased complexity, diversity and dynamics in consumer demand was forcing the whole business system to be more complex, more flexible, and more dynamic than ever before. The complexity propagates towards the supply chain among different stakeholders. The list of stakeholders in fashion chain is long, i.e. suppliers (fibres, machinery and chemicals), manufacturers (clothing and textiles, including technical textiles), retailers and fashion bureaus; post-consumer actors; service providers (software, consultants, press, industry associations) and independent experts (scholars), the supply chain (SC) . and it grows truly complex as de Brito et al. (2008) state. The trend of outsourcing extended the span of company's operations and increased dependency to the external parties. Outsourcing is being driven by a desire to reduce the cost of operations, and the need for business flexibility to respond quickly to changing markets (Shelton \& Wachter, 2005).

The present fashion market is demanding and such dynamic market asks products to be sometimes delivered even in three to four weeks' time from design to stores. The flexible nature of the market compels traditional operations to adapt agile strategy. As the fashion product supply chain is quite long and often consists of many different phases, therefore meeting the demand of the market is challenging. Although often the raw material and initial production process (such as weaving and stitching) may remain the same for multiple products from the same retailers, yet supplier has to start the raw material procurement and production process way before the order is received from retailers (Banerjee \& Golhar, 2013). A close collaboration throughout the chain is a must as operations and manufacturing steps are interdependent. Because current competition does not just concern the individual firm but, rather, involves the entire SC (Jin, 2006).

Christerson \& Appelbaum (1995) state that most firms which market brand-name labels in apparel do not take part directly in any manufacturing activities, but focus on design, marketing and retailing. Manufacturing operations are mainly outsourced under the direct supervision of the brands or through the third party agents. As denoted by Gereffi (1999), generally the SC is led by large retailers, branded marketers, and branded manufacturers who set up decentralized production networks in a variety of exporting countries. The evolution in fashion industry reformed from the customary supply chain management (SCM), which is apparent in many studies. Because of the extended external network and lack of direct control in manufacturing demand management is challenging. Demand change management (DCM) emerges as an effort of combining marketing with supply process for handling the demand. The approach of combining the demand chain and supply chain management has brought by the academicians at a later stage as a succession of DCM, which is quoted as demand supply chain management (DSCM).

This study focuses on DSCM which is based on a systematic literature review of textile and apparel supply chain and also demand chain management of the forerunner fashion brands. The study is in search of two principle research questions: How the demand-supply is operated by the retail brands which deal with more fashion sensitive and less fashion sensitive apparel products? How to manage and organize the demand supply chain (DSC) based on fashion sensitivity? To clarify these issues, textile-apparel demand and supply management of the DSC is studied through a literature review. The study concerned with the evolution and explanation of DSCM. To understand better the DSCM, present status of the fashion market is studied and also analysed how the market is evaluated among the brands towards quick response settings. To get the picture about the complexity of the fashion supply chain, the textile and apparel processing stages are briefly discussed by dividing the operations from the supply side and demand side. Afterwards, composition of DSC in textile and apparel sector and its consequences are presented.

\section{Demand Management in the Supply Chain}

SC is implored with different demands and requirements while got attracted as a standalone way of managing the operations. The requirements in SCM vary with time, for instance, researchers considered marketing as an integrated part of the SC in recent times. Seeing the increasing need to integrate key elements of SCM (e.g. demand fulfilment with a focus on efficiency) with marketing (i.e. demand creation with a focus on responsiveness), researchers have been advocating the concept of DCM (Lau, 2012). Demand creation and demand fulfilment are different activities in an organization although mutually dependent on each other. It is realized in the researches and the notion that DSCM is evolved as an extended footstep towards operational improvements through the integration of demand and supply side of organizations. Esper et al. (2010) define demand and supply integration as the balancing of demand and supply market information and business intelligence through integrated knowledge management processes to strategically manage demand-supply activities for the creation of superior customer value. 
SCM has first appeared in 1982 which is defined as efforts to reduce inefficiencies and solve the problems throughout the SC, from raw materials to final customers (Lee \& Kincade, 2003). SCM shifts the mindset from single organization perspective to multi-actor co-operation. Heikkilä (2002) advocates that the SCM concept extends the view of operations from a single business unit or a company to the whole SC. On the other hand, DCM is relatively a new concept which integrates SCM with demand generation through marketing effort. Demand management in the supply chain is about the value creation throughout the SC which reflects customer's hope. Hilletofth et al. (2009) shows that DCM is about developing synergies between the demand creation and the demand fulfilment processes which comprise all the activities necessary for creating demand and is closely linked to the marketing discipline, whilst the demand fulfilment processes comprise all the activities necessary for fulfilling demand and is closely linked to SCM. De Treville et al. (2004) mention that demand integration includes increased access to demand information throughout the SC to permit rapid and efficient delivery, coordinated planning, and improved logistics communication. Madhani (2015) describes DCM that provides the alignment of demand creation and demand fulfilment processes across functional, organizational and inter-organizational boundaries that can leverage the strengths of marketing and SCM and meet the challenges of customer value creation in today's marketplace. Although it is suggested to integrate demand in SC, Rainbird (2004) suggested that rather than seeking to merge or harmonise what are two quite distinct concepts, it is better to see supply and demand chains as being inherently in conflict within the context of the organisation's overall value chain.

Albeit DC and SC distinct concepts, Hilletofth (2011) urges that the need to coordinate the demand and supply processes has been emphasized in both the DC as well as the SC literature. Both demand and supply chains deal with demand. DCM attempts to analyse and understand the overall demand for markets within the firm's current and potential product range (Rainbird, 2004). They also mention that SC, by contrast, emphasizes the efficiencies in the production and logistics processes, while the DC emphasizes effectiveness in the business. Esper et al. (2010) define demand side activities as relating to individuals and processes both inside and outside the focal organization that are responsible for generating and maintaining demand, and supply side activities relating to the individuals and processes both inside and outside the focal organization for managing operational areas that support and supply the products and services necessary for demand fulfilment. Hwarng \& Xie (2008) investigated the various supply chain factors contributing to the complex dynamics and chaotic behaviours and found that among others demand pattern and demand information sharing was exigent. Christopher \& Ryals (2014) state that the fundamental change, from supply chains to demand chains, is being driven by market forces and enabled by new technologies. The power locus is shifting steadily downstream, from producers and retailers to buyers and users. Hilletofth (2011) compares how companies are attaining competitive advantages by DCM or SCM and states that those embracing the demand-led business model (demand chain masters) focus on coordinating and managing the demand processes (DCM) by providing superior customer value while companies embracing the supply led business model (supply chain masters) focus on coordinating and managing the supply processes (SCM) to obtain a competitive advantage by providing comparable customer value at lower cost.

Demand-supply chain formation is the aggregation of demand and supply chain to interact at some point which is termed as order penetration point (OPP) and value-offering point (VOP) as entitled by Holmström et al. (2001). As defined by them, OPP is the place in the SC where the supplier allocates the goods ordered by the customer and VOP as a meeting point of the DC and SC where the supplier fulfils demand in the customer's demand chain. They also argue that manipulating the DSC does more than improve customers' performance and benefit suppliers. The overall approach is to create a complementary situation where the demand is utilized without producing the waste and moving towards a sustainable way of SCM. According to Christopher \& Ryals (2014), the supply chain needs to be designed from the customer backward (demand pull) instead of from the factory outward (supply push), making it responsive to customer demands and reducing waste and returns. Hilletofth (2011) sees the goal of DSCM is to gain a competitive advantage by providing superior customer value at lower cost, and this is achieved by organizing the company around understanding how customer value is created cost efficiently (managing the DC), how customer value is delivered cost efficiently (managing the SC), and how these processes and management directions can be coordinated. He emphasizes on competences, a company established principles, DSC collaboration, and information technology support in order to achieve the benefits of DSCM which includes enhanced competitiveness, DC performance and SC performance. Figure 1 depicts the idea of DSC. 


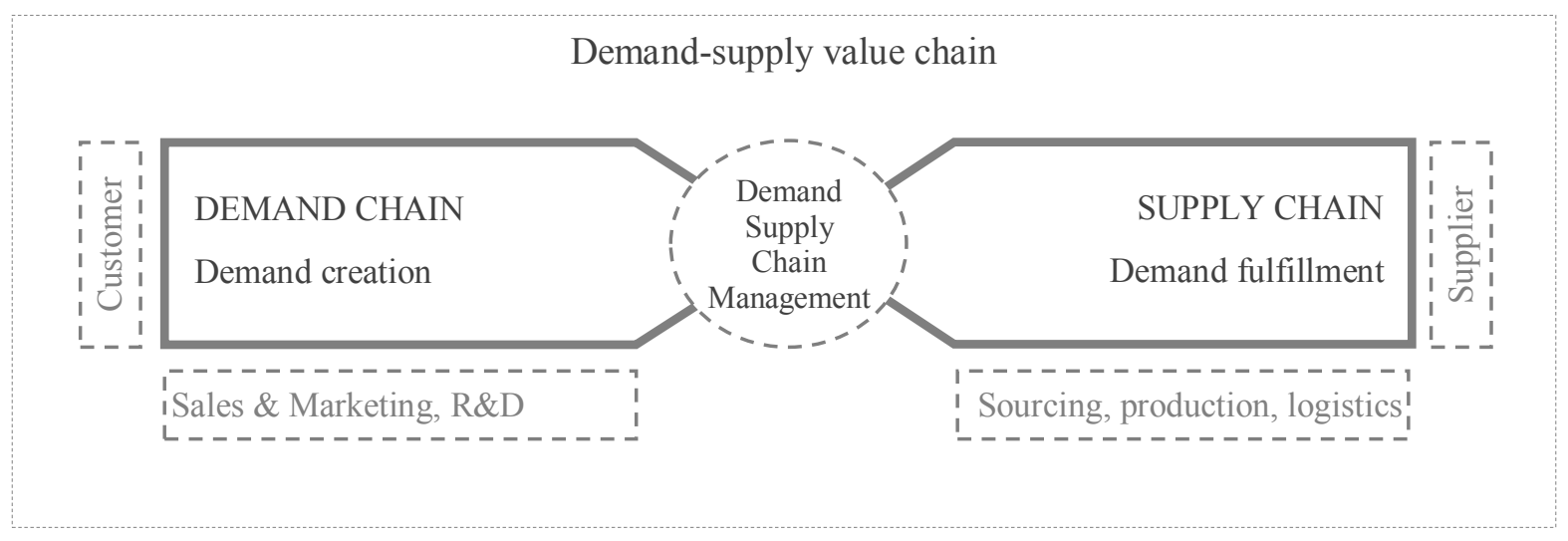

Figure 1: Demand-supply value chain

\section{Evolution in the Fashion Industry}

The fashion industry is particularly a dynamic sector in which to explore the retail buying decision-making process, due to its characteristics of increasingly shorter product life cycles, a high level of product variety and an inability to accurately predict consumer buying behavior (Perry \& Kyriakaki, 2014). The complexity arises with the emergence of new consumer groups, new markets, and new trends in sourcing, which was not common few decades ago. According to Masson et al. (2007) one of the major market developments has been that modern fashion has become democratized and egalitarian. In the course of the last two decades, the fashion apparel industry across the globe has undergone deep transformation due to various changes in the business environment (Bhardwaj \& Fairhurst, 2010). Consumers in modern times are more fashion conscious and looking for new options continuously. Consequently, the length of the use of a particular apparel product is shortened significantly. Barnes \& Lea-Greenwood (2010) argue that there is a decline in the length of fashion product life cycles which has put pressure on retailers to replenish more frequently as they simply need more product ranges to keep up to date. The trend also provoked the emergence of the fast fashion concept which has got an extensive success till today. To get an extended view about the change occurred, this section provides an overview of fashion market's diversity, change from mass manufacturing to the quick response concept and operations of top brands under present circumstances.

\subsection{Formation of Fashion Market}

Fashion is a broad term which is defined by Christopher et al. (2004) that is typically encompassed any product or market where there is an element of style that is likely to be short-lived. They have divided the fashion market based on four characteristics. Products fallen into short life-cycle category are saleable for a very short period and these are seasonal. High volatile product group's demand is very unstable and influenced by weather, films, or even by celebrities. Products whose demands are extremely difficult to forecast are categorized as low predictability. High impulse purchasing is happening when shopper confronted with the product is stimulated to buy it. Different product groups has different kinds of impact on the market demand fulfilment and upstream influence. Vrontis \& Vronti (2004) mention a diversity of factors, including socio-cultural, legal/political, physical, environmental, technological, demographic, competition and economic that determine whether the marketing mix can be standardised for all customers or whether it needs to be adapted to suit specific market conditions. Product characteristics emerge immediately as an aspect that cannot be neglected to compete in the fashion market, at least due to differences in the competences, which are required for manufacturing and distributing products (Brun \& Castelli, 2008).

The changes in fashion industry happen rather fast. In the past centuries, clothing was regarded by most people as a necessity and therefore apparel manufacturing mainly had a functional purpose (Brun \& Castelli, 2008) which means that complexity related to product characteristics was less. As a result fashion market was rather uniform. They also add that most fashion industries generally launch two collections each year, corresponding to the main seasons (fall-winter and spring-summer) and also offer evergreen products, or classics, which remain on the market for multiple seasons. Apparel on those early days used to fulfill the need for basic functionality, for example serving the purpose for protecting from cold or comfort during summer. Apparently, consumers during that time were less sensitive to style and fashion, and preferred basic apparel (Bhardwaj \& Fairhurst, 2010). 
Today's consumer is more inclined to look beyond traditional retail venues for shopping alternatives which means more options for shopping is a requisite and on top of that they are even interested in personalizing their apparel (AndersonConnell et al., 2002). As a consequence fashion market is highly competitive and the constant need to 'refresh' product ranges means that there is an inevitable move by many retailers to extend the number of 'seasons', that is, the frequency with which the entire merchandise within a store is changed (Bhardwaj \& Fairhurst, 2010). So, the main difference between the early days and modern time is consumer sensitivity on fashion.

\subsection{Market Shift towards Fast Fashion}

Until the mid-1980s, success in the fashion industry was based on low cost mass production of standardized styles that did not change frequently due to the design restrictions of the factories (Bhardwaj \& Fairhurst, 2010) as the demand in apparel market was more homogeneous. Outsourcing trend by the western brands enabled lowering the price of the product. When the supply chain has learned the conduct of the functionality, it was becoming agile and able to offer varieties. The supply chain agility is the key towards the shift from mass production to fast fashion. The changes in the fashion industry have been occurring rather rapidly within the trend of shift and the impact is drastic, especially on apparel supply chain operations. Cao et al. (2008) argue that the changes are attributable to the fickle consumer demands and more customized market requirements. Meanwhile, mass customization evolved as another concept to provide individual consumers with products tailored to their specific wants, and these customized products are manufactured in a mass production arena, allowing them to be sold at prices reflecting economies of scale (Anderson-Connell et al., 2002). It indicates that market was demanding for more varieties and even personalization through customization. So the demand is seen already before real fast fashion trend started and the trend of fast fashion just not evolved suddenly. Tokatli (2008) admits that even though clothing retailers in the industrialized core have favoured a strategy of increased variety and fissionability since the 1980s, 'fast fashion' principles have recently reinforced that strategy even further.

Fast fashion is a concept whereby retailers orientate their business strategies to reduce the time taken to get fashion product into store, working on a system of in-season buying so product ranges are consistently updated throughout the season (Barnes \& Lea-Greenwood, 2010). This is actually the concept behind the trend, however it is seen that the successful brands have their own way of managing the concept. Runfola \& Guercini (2013) point that although fast fashion has been considered by academics and managers as a "unique model", previous work has demonstrated the huge variety of "fast fashion" formulas adopted in the real world. By including consumer demand as a facet of fast fashion, they suggest that in-season buying and reduced lead time concept incorporate "newness" as a key feature of fast fashion, in other words, continual renewal and updating of ranges and merchandise delivered to the store. Bhardwaj \& Fairhurst (2010) state that the concept emerges from the constant need to 'refresh' product ranges to extend the number of 'seasons', that is, the frequency with which the entire merchandise within a store is changed. They add that by small collections of merchandise, fashion retailers are encouraging consumers to visit their stores more frequently. Tokatli (2008) points out that fast fashion requires the retailers have rapidly increasing numbers of stores worldwide — preferably directly owned and operated outlets in secure countries and franchised outlets in risky ones - so that they can reach more and more customers around the globe.

\subsection{Adaption of Changes by the Brands}

Since the introduction of first jeans in 1873 (Levi Strauss \& Co., 2014), Levi's is one of the world's largest brand-name apparel marketers with an unparalleled global presence of more than 100 countries which are sold under the brand names Levi's and Dockers (Vrontis \& Vronti, 2004). The changing and demanding trend in fashion business had an extensive impact on them. They explain that it was under pressure to lower the prices of its clothes which has put pressure to reduce workforce and cease operation of some of its own facilities. The global outsourcing trend in the early nineties pushed them to outsource from less expensive resources to keep them competitive. Levi's forced to reorganize its strategy which resulted affordable Signature brand. Although they were offering more affordable priced product to the customers, they were putting effort on providing more options to the consumers. Levi's have been trying to customize jeans for several years, offering consumers choices within a range of style, colour, and fit (Anderson-Connell et al., 2002), which was not a successful campaign at the end. But recently they have re-launched the mass customization concept offering "Made to Order" jeans for individual customers. In addition, Levi's emphasized on sustainability through green campaign, better cotton initiative, and waterless products. So, they are not following the footsteps of fast fashion, but yet try to offer versatility in their product range. 
Nevertheless, Levi's was struggling with the flourishing aptitude of less expensive and trendy products as ecological campaign is also not uncommon by those brands. It is not only the low price, ecological product, fit, brand image that is offered by the brands which makes the difference, but the consumer behaviour and market need is one of the chief moderators. Barnes \& Lea-Greenwood (2010) argue that there has been a decline in the length of fashion product life cycles which has put pressure on retailers to replenish more frequently as they simply need more product ranges to keep up to date. Fashion from the catwalks that might have been exclusive in the past is now often widely available on the high street in weeks (Masson et al., 2007). The prime user of fast fashion concepts like Zara, H\&M, and Gap organized their operations to refurbish products many times in a year. Firms like Inditex (Zara) and H\&M are able to produce apparel from design to distribution in three to eight weeks (Jacobs, 2006), which allows them to renew the stores frequently.

Zara is one of the pioneers to use the fast fashion concept to manufacture and retail clothing successfully. Zara introduces approximately 11,000 new products each year, resulting in a much shorter product shelf life (Banerjee \& Golhar, 2013). From the drawing board to store racks, new fashions can be brought into the markets in 2 weeks (Chow et al., 2008). The traditional product development and product offering which was based on two main seasons is extended. According to Runfola \& Guercini (2013) it is increased up to four or even six seasonal collections. From the design point of view, it is continuous product development round the year where seasons have an impact to develop products rather than the collection based on season. It is clear that the target is to offer a wide option for the customer according to the current trend and also at an affordable price.

Runfola \& Guercini (2013) highlight the international expansion of some successful fast fashion companies (namely the two leading examples, Inditex-Zara and H\&M towards foreign markets, especially towards European countries. Zara has over 2,000 stores strategically located in leading cities across 88 countries (Inditex, 2015). Their international market positioning places it in direct competition with some of the most skilled operations in the business, including Italian fashion giant Benetton and U.S.-based Gap and The Limited (Christopher, 2000) and also H\&M. The whole process of supplying goods to the stores begins with cross-functional teams-comprising fashion, commercial, and retail specialistsworking within Zara's design department (Christopher, 2000). They have their own tightly linked and vertically integrated SC that is attributed by many as key to its success (Banerjee \&Golhar, 2013). Almost uniquely they have developed SC processes that enable them to capture ideas and trends in the apparel market and to translate them into products in amazingly short lead times (Christopher, 2011), through closely connected, highly synchronized arrangements with internal and out-sourced suppliers (Christopher \& Lee, 2004).

Zara's specialist design team constantly collects the customers' feedback. A creative team consists of over 200 professionals forward those to product development. Besides efficient design process, they have organized material sourcing and product manufacturing which are strategically located in different places. Raw materials are procured through the company's buying offices in the United Kingdom, China, and The Netherlands, with most of the materials themselves coming from Mauritius, New Zealand, Australia, Morocco, China, India, Turkey, Korea, Italy, and Germany (Christopher, 2000). The product range is strategically divided in order to produce the fastest among fast from the adjacent facilities and the least amongst to take competitive advantage of relatively inexpensive resources. It also uses a postponement trick in its SC by keeping the utmost raw material in unprocessed form. The material or fabric is also held in "Greige" (i.e., undyed and unprinted) and, if demand for a particular garment turns out to be higher than expected, local manufacturers can then quickly manufacture additional products (Christopher, 2000).

\section{Textile and Apparel Processing}

Textile and apparel processing consists of a number of activities prior to stitching task which is usually more focused when parley about the apparel product. The process of an apparel product production is quite long and the process continues like in a pipeline. The traditional pipeline system starts with an idea about a product, often generated from a forecasted fabric or color, pushes that idea through a lengthy product development period as well as through extensive business-to-business market and production processes, and concludes with a push type sale to a final consumer (Kincade et al., 2007). Cao et al. (2008) mention textile-apparel SC is relatively complex because it encompasses several chunks of manufacturing processes such as fibre and yarn processing, fabric manufacturing/finishing, garment manufacturing and retailing. They have found a such SC to be similar to conventional forms of SC, i.e. the vertical integration process in which steps of production and/or distribution of a product are controlled by a single company or functional entities of an enterprise, in 
order to increase that company's or entity's power, mainly in terms of cost or time efficiency, in the marketplace. Although Cao et al. (2008) state that vertical integration is not so common nowadays and even such integration exists, it is only part of the company's business. This section aims to provide a supply side overview of textile-apparel manufacturing operations where the minor or side-line operations are not presented elaborately.

\subsection{Textile Processing Prior to Apparel Production}

The textile processing phases are long and extensive. A generic textile SC has for its primary raw material vendors, cotton growers and/or chemical suppliers, depending upon whether the end product is cotton, polyester or some combination of cotton and polyester garment (Kumar, 2001). In this chain, materials usually flow in one direction, and excluding minor quantities for testing materials and designs, starts with fibre production (Seuring, 2004). The textile processing starts with the fibre production which compose the final apparel product. Therefore properties of final product have an impact very deep in the chain. Fibers are usually classified into two groups: natural and man-made (Sen, 2008). Cotton is cultivated around the world which is transported to spinners either domestically or internationally. Man-made fibers (i.e. synthetic fibers) are another very essential fiber source which accounts for nearly $60 \%$ of the apparel product at the time of analysis (U.S. Congress, 1987). Both natural and synthetic fibers become yarn through spinning. Spinning is the final, most costly part of the conversion of fiber into the yarn (Gillham et al., 1995). Whether or not the spinner is vertically integrated with the weavers and apparel manufacturers, it produces the yarn as required by the weavers to meet the retail buyer's specification. From SC perspective, typically yarn suppliers are chosen by weavers, but often spinners develop new yarns by their specific competence in this field which may motivate retailers for developing new products.

After the extensive fibre processing, weaving transforms yarn into fabric by interlacing lengthwise warp yarns and widthwise filling yarns at right angles (U.S. Congress, 1987). Fabrics produced by weaving or knitting required good and constant yarn quality. Because of the advancement of weaving and knitting technology, equipment are faster than before which need high-quality yarns to reduce the yarn breakage rate and efficient production. The warp yarns are at times dyed with the yarn dyeing process before the weaving. A typical example is denim fabric where warp yarn is dyed with indigo through yarn dyeing. Warp dyed or raw yarn is woven with numerous constructions by various weaving methods. Yarns are transformed into fabrics also by knitting and Non-woven processes. Non-woven processes involve compression and interlocking fibers by mechanical, thermal, chemical or fluid methods (Sen, 2008).

Yarn processing and fabric manufacturing also influenced by the present fast track trend. Chen \&Harlock (1999) state that textile industry is facing ever-increasing competition in the global market, which demands production flexibility and quick response to customers. It means that the market is demanding more variety of fabric styles, smaller order sizes, and shorter delivery times. However, there is a significant difference between textile processing and apparel making. Textile processing stages are often batch or continuous processing which has a minimum limit to produce, whereas apparel products are produced in pieces.

Weaved and knitted fabrics are called "greige" contains impurities and requires further processing. The typical fabric processing stages involve pre-treatment of textiles, dyeing or printing and finishing. Seuring (2004) interprets textile industry is a global one where fibres might be produced in one country, yarns may be in other, fabric may be woven in a third country and stitching in somewhere else. He also adds that the textile chain is based on supplier and buyer relationship and it neglects the multiple sidelines employed to build these products, e.g. the chemicals needed in the production process or sewing yarns. Chemical suppliers at different stages in textile-apparel SC play a very important role and have a direct impact on product quality, process improvement, new technologies, and new finishes. All of the textile processing stages like yarn processing, sizing, pre-treatment, dyeing, finishing are chemical intensive.

\subsection{Apparel Processing}

Since the production of mechanical sewing machines in the 1850s, sewing apparel products has always been and remains a labour-intensive activity with small capital investment requirements (Abernathy et al., 2006), which allows the industry to spread widely especially in the low-wage areas. Although automation in cutting and sewing is seen in present time, the elimination of physical labour is not significant. Apparel processing is, therefore, manual type operations and consumes a lot of physical and time resource. From the SC point of view, apparel manufacturing is the continuation of the extensive textile processing which consists of a series of operations, including pattern, assortment, fabric handling, cutting, stitching, dry and wet processing, garment dyeing, finishing . 
Undeniably many parties involved in textile-apparel operations which might be from same apparel composite or independently specialize bodies like dry or wet processing companies. There are many sideline actors like chemical and dyestuffs suppliers, accessories suppliers, embellishment service providers, quality testing services play a very important role in apparel manufacturing. Apparel manufacturers play an important role as they are considered as first tier supplier. Buyers often have direct communication with this tier and apparel producers' deal with the rest, e.g. second and third tier. It is not uncommon that an apparel producer sources the raw materials, components and others on behalf of buyers and as per their requirements.

Retailers or distributors are often closely integrated with the apparel manufacturer; even some of them are vertically integrated. For example, Christopher (2000) alludes that Zara uses its own highly automated factories and a network of smaller contractors for quick response. However, Christerson \& Appelbaum (1995) argue that apparel production is vertically disintegrated, transactions-intensive, and involves extremely volatile demand conditions and highly specialized niche markets. They observe that it operates through subcontracting networks where the cut fabrics, along with buttons, zippers, or other components, are delivered to an independent sewing contractor. However, after the extensive effect of globalization, such segregating activities are not so common. Although the principal players are often retailers and apparel companies, each member of the textile-apparel chain has its valuable contribution, as Chandra \& Kumar (2000) mention that each member of the textile SC possesses specialized knowledge about the textile business. They add that the collaboration is mutual as the apparel maker acts as a consumer of fabric, while dealing with a textile manufacturer (a provider of fabric). The long supply pipeline makes the lead time of the textile-apparel SC relatively long and uncertain in response to the volatile characteristics of fashion markets (Cao et al., 2008). For this reason the growth of cooperation between the actors in the SC is important for the sake of quick response in order to meet demand of the present market.

\section{Demand Side of the Apparel Chain}

This part of the study focuses demand side of the textile-apparel chain as a distinct part where it is separated from manufacturing operations. DC operations are mainly non-production activities which are concentrated to the activity of a retailer who is a brand owner as defined by Cao et al. (2008), or it can also be treated as a distributor and a retailer. Many fashion brands in western economy only deal directly with this part of the chain and not directly involved in manufacturing. Practically retailers or brands are detached from the suppliers in most cases because often they source their products from independent manufacturers. For example, Benetton uses both franchising and sub-contracting, although Zara is vertically integrated which maintains significant upstream clothing production, some retailers use an independent trading company like Li and Fung (MacCarthy \& Jayarathne, 2013), Levi’s obtains products through own nominated suppliers .

\subsection{Design and $R \& D$}

Design is the core feature of a brand by which it distinguishes themselves from others. Design is usually done by focal companies in the SC (Seuring, 2004) which is either completed in-house or by design firms where the design process first analyse the consumer need and motive as Sen (2008) adds. The information often collected from the fabric exhibitions, fashion shows, trade shows which are getting importance nowadays as recent years have seen fashion retailers compete with others by ensuring speed to market with their ability to provide rapidly the fashion trends revealed by fashion shows and runways (Bhardwaj \& Fairhurst, 2010). Mutual co-operation with the fabric or apparel manufacturers are also not uncommon. By collecting the idea for designing, brand owners initiate the product development process which is according to Cao et al. (2008) includes research and design. Commercially viable design and product development process is critical for demand fulfilment and growth and also for efficient SC operation. As the manufacturing operations are outsourced by most, it is critical that the designs are producible efficiently. The change of design during manufacturing is impractical and expensive.

Seuring (2004) argues that sometimes product design \& development integrate to either side of the SC, i.e. they perform some stages of production or distribution and sell the apparel they buy from suppliers. In a competitive fashion business condition the lead time is compressed exceedingly both for sample making and bulk production. Prototypes are required to produce much faster than before as it consumes a considerable amount of time according to Sen (2008). The correction of design and remaking of new sample also complicates and lengthens the process. Some of the designing process is comprehensive as brands involved in developing fabrics or even fibres rather than just selecting materials. Trendy products 
often required a considerable amount of embellishment work which is subject to trial and error. Therefore a continuous product development process is quite common for the brands. Prototypes are finalized after necessary corrections followed by preparation of production samples. It is worth mentioning that the prototypes are prepared by the suppliers in general.

\subsection{Retailing and Distribution}

Retail operation occupy the top of the chain which consists of sales related activities like buying merchandise, operating stores and operating warehouses (Sen, 2008) although often those tasks are carried out by an individual responsible person or department. Retailers maintain relationship with the suppliers in various ways through direct interaction, retailer's regional office, manufacturer's regional office, independent retail agent, trading company as classified by MacCarthy \& Jayarathne (2013). As Lee \& Kincade (2003) explain, retailers select vendors, primarily on a cost basis, the advantage emerges as manufacturers compete for retail business. On top of this, few more criteria like product fashion level, product quality level, operational performances, financial stability, ethical and ecological requirements influence the selection and cooperation with suppliers. The extent of interference by retailers directs the DSC. For example, some retailers decide about the fabric, accessories, packaging or even logistics.

Apparel items that are produced by garment manufacturers are sent to distributing channel from brand owners to retailers (Cao et al., 2008). Selling and distribution can be carried out by a single company or within a distribution system (wholesalers, retailers) of varying depth and the mode of this operation is linked to product design (Seuring, 2004). Sen (2008) provides the process description where assembled garments are labelled, packaged and usually shipped to an intermediate warehouse before shipping to the retailers' warehouse. These distribution centres are also handling many important activities at times. Especially, when the distribution centres are dealing with many different countries, they have to deal with country-specific labelling, regulations. Sen (2008) also mentions that in order to compress the time from placement of the retailer's order to the consumer's purchase, responsibilities are often shared with the manufacturer where they are labelling products with retailer's price tags, preparing them on hangers and in some case shipping them directly to stores.

\section{Demand Management in the Supply Chain}

We illustrate how engineering schools and business schools can use a regional approach in a globalized world, aiming for economic growth. We show that technology and leadership can have an influence on value creation. We regard technology as the main change agent. A focus on technology can also have a positive effect on communication among actors in the business community and in the public sector. At first stage businesses within regions will probably use knowledge on a trial-and-error basis using technology to change routines. In the longer run changes in routines are assumed to lead to strategic change leading to economic growth. More research is necessary to find out more about how actors can co-operate in networks, paying attention to routines. A global focus means that intangible resources become more important moving to a broader approach involving more than economic parameters. Value creation should also have a broad approach involving social as well as economic parameters.

This paper focuses on the DSC in the fashion industry by assessing demand side and supply side of a value chain which is according to Jacobs (2006) different perspectives on one chain or value system and the argument is that the distinction provides a clearer view of the structure and operation of DSC. Although distinct they are interdependent and have a great influence on customer service. Customer demands and feedbacks are coming through the demand channel, whereas supply side should consider those as inputs to meet the requirements. Product creation and product demand fulfilment in a company cannot be dealt independently. This is the justification for the DSC where segment specific importance is perceived by others in the supply chain. DSCM requires a veritable collaboration between marketing and supply chain, because as denoted by Lee \& Kincade (2003) traditionally in the apparel industry, each chain member runs its business based upon separate concerns and interests, sometimes causing conflicts in the relationships with chain partners. The conflicts are not only on supply chain specific issues like performance, quality, economic, logistics., but also other important issues like sustainable production, regulatory requirements, product details .

DSCM tends to amalgamate those individual interests to group interest as Chandra \& Kumar (2000) states that each member pursues its own goals, objectives, and policies conceptually, independently of the group, but pragmatically in congruence with group goals. The motive of the DSCM is to gain a superior competitive advantage by creating customer value cost efficiently (Esper et al., 2010; Hilletofth, 2011). 
Esper et al. (2010) also mention that the integration represents a strategic approach to bundling the customer value propositions from both sides to create value in the marketplace. Hilletofth (2011) mentions about market orientation, equal importance on demand and supply, value creation, processes differentiations, process coordination, innovativeness, responsiveness and cost efficiency in the demand and supply processes. Market orientation is to some extent evident to the apparel companies (e.g. Zara, Benetton) where the partial SC with own manufacturing integrated into DC that delivers superior customer value cost efficiently. However, a true coordination only possible when demand and supply is equally important for value creation (Heikkilä, 2002; Rainbird, 2004; Holmström et al., 2001; Hilletofth, 2011) and coordinated accordingly. The partnership is critical to produce a wide assortment of a single style in small quantities which is an essential requirement of present market run by fast fashion strategy. Also there could be additional requirement of small quantity with the successful products. Design is critical driver for the successful operation throughout the chain. Design flexibility can facilitate the supply side activities and provide flexibility and more options. The demand side also in the loop after the manufacturing where it is in between the consumers and manufacturers and issues related to product, quality, delay are needed to be dealt by them. A retailer's DC would consist of assortment planning (deciding what to sell), inventory management (deciding the quantity of supplies needed), and the actual purchase, which together with SC form the DSC (Holmström et al., 2001).

The development of new, quick fashion appears symptomatic of the transition from a production-driven to a market-driven approach in the fashion apparel industry where the markets have become more varied and faster-changing in the present retail environment (Bhardwaj \& Fairhurst, 2010). The utilization of agility in supply chain is utilized not only by the fast fashion brands, but it got attracts by almost all other. However, agility should be throughout the chain, i.e. from concept until store. The principle idea is that each organizes their own SC according to the need, product type, and market. The mentioned brands in this study and few brands utilized the fast fashion concept through process differentiation. H\&M and Gap introduce 2,000-4,000 new items each year, Zara able to supply new products in each 3-6 weeks (Tokatli, 2008), whereas traditionally the fashion chain leading to a new season has taken even about 18 months (Jacobs, 2006). Zara has differentiated their DSC exceptionally with innovativeness and utilized responsiveness feature by organizing the DSC where superior customer value is realized. They want to have quick turnover of the goods in store. They have integrated important aspects like material, product group and accordingly they have organized the supply base from near shore or offshore. Other fast fashion leaders like H\&M, Gap and Mango have been able to implement the mentioned features without having their own manufacturing facilities, but still being able to deliver their products reasonably quicker. Retailers and brands like Levi's are not following the same method which is seen in recent apparel DSCs, although they are also outsourcing most of their products.

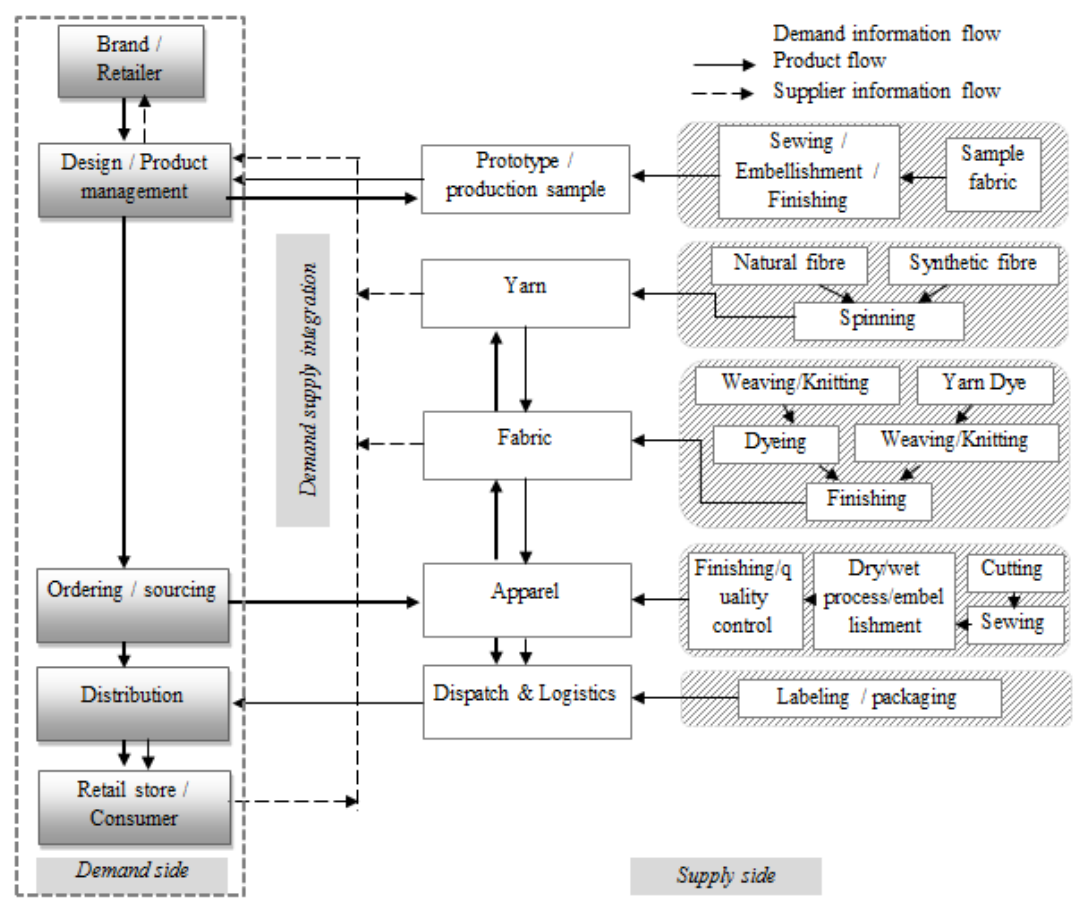

Figure 2: Textile-apparel demand-supply chain 
Unfortunately, coordination in textile-apparel SC is still an unresolved question both from the theoretic and practical points-of-view (Cao et al., 2008). It is not uncommon that design and manufacturing remains as two different entity where the real co-operation is missing. MacCarthy \& Jayarathne (2013) apprise that the retailer or brand owner, as the buying entity, is powerful and influences the structure, relationships and operational practices across the network. According to them a typical scenario is that a retailer based in a developed western economy works with a specific prime manufacturer based in a clothing production region in a less developed economy to supply a particular type of garment. Similar scenario also evident among the brands considered in this study which do not own manufacturing and have to rely on the suppliers. In some cases brands even don't know who the producer of their products is and in which condition as some of the brands are sourcing their products through agents who have a supplier network. Because most fashion firms rely on other partners for an important part of their value system, shortening the SC requires increased fine-tuning with these partners (Jacobs, 2006). Therefore, to gain a true DSC the interests of all parties should be secured mutually and truthfully which will lead to reconstruct the value chain. The reliance is important for sharing information throughout the DSC.

\section{Conclusion and Future Research}

DSCM is a cutting-edge method of managing value chain which encompasses a wider perspective from customer oriented marketing to demand fulfilment activities. By reviewing existing researches on various perspectives of demand and supply and wandering web resources, this study attempted to investigate the researches on DSCM and its association to textile and apparel retailing and manufacturing. There are a significant number of researches found related to SCM and a considerable amount on DCM is observed especially nowadays in this sector. In most of the fashion chain literature, the emphasis is seen from retailing and marketing perspective and the manufacturing segment dominated by them. However, combining the demand and supply perspective in fashion chain exclusively is inexistent. The study also reveals that researches in textile and apparel DSCM are not ample and this is the motivation of the contribution to this effort. This study tries to fill the gap to bring the demand and supply mutual and complementary co-existence in the same value chain. The connection and essentiality of DSCM with fast fashion concept are more noteworthy. However, it opens up the scope for the retailers running the SC traditionally and does not hold the same view as fast fashion retailers. Further research through specific case study can examine how the less fashion-sensitive brands can adopt and benefited by DSCM. At least non-value adding activities can be minimized and processing pace can be improved which may lead to different scope in their business. Whether it is fast fashion or so-called slow fashion, both would need their product on-time to the stores.

The conjunction of DSCM with other aspects like consumer segmentation, product and product pricing segmentation deserve ample research. According to this research it is evident that there are lot of open possibilities when demand and supply are reciprocally combined. The organized study in textile and apparel supply and demand chain provides the ground for developing the framework for the application of DSCM in this sector. Experts in demand side can have better view on supply side and vice versa. The drivers of demand-supply integration is widely discussed and it is also shown that the elements for the integration existent to some of the retailers in this review. The comparative picture exposed the gap between successful retailers and the similar retailers based on the quick response concept. The apparel market is affected by the fast fashion concept widely and presumably trend will continue in the same direction. Even it is not fast fashion, brands would like to include new products in efficient manner. Therefore, in addition to the present research related to SCM or DCM of fast fashion, emphasis should be put on further investigation on the DSCM on fast fashion and for others. It is also necessary to inquire, how the same interest can be propagated to different members of a SC, especially when it is not vertically integrated. It is critical because extremely quick response requires consensus at all levels of DSC, although individual firms preserve their own interest.

\section{References}

- Abernathy, F.H., Volpe, A., \& Weil D. (2006). The future of the apparel and textile industries: prospects and choices for public and private actors. Environment and Planning A, 38(12), 2207 - 2232, CrossRef

- Anderson-Connell, L.J., Ulrich, P.V., \& Brannon, E.L. (2002). A consumer-driven model for mass customization in the apparel market. Journal of Fashion Marketing and Management: An International Journal, 6(3), $240-258$, CrossRef

- Banerjee, S., \&Golhar, D.Y. (2013). A decision support system for a third-party coordinator managing supply chain with demand uncertainty. Production Planning \& Control: The Management of Operations, 24(6), 521531, $\underline{\text { CrossRef }}$ 
- Barnes, L., \& Lea-Greenwood, G. (2010). Fast fashion in the retail store environment. International Journal of Retail \& Distribution Management, 38(10), 760 - 772, CrossRef

- Bhardwaj, V., \&Fairhurst, A. (2010). Fast fashion: response to changes in the fashion industry. The International Review of Retail, Distribution and Consumer Research, 20(1), 165-173, CrossRef

- Brun, A., \&Castelli, C. (2008). Supply chain strategy in the fashion industry: Developing a portfolio model depending on product, retail channel and brand. Int. J. Production Economics, 116, 169-181, CrossRef

- Cao, N., Zhang, Z., To, K.M., \& Ng, K.P. (2008). How are supply chains coordinated? An empirical observation in textile-apparel. Journal of Fashion Marketing and Management: An International Journal, 12(3), $384-397$, CrossRef

- Canever, M.D., Van Trijp, H.C.M. \& Beers, G. (2008), The emergent demand chain management: key features and illustration from the beef business", Supply Chain Management: An International Journal, Vol. 13, Iss 2, pp. 104-115, $\underline{\text { CrossRef }}$

- Chow, W.S., Madu, C.N., Kuei, C-H., Lu, M.H., Lin, C., \& Tseng, H. (2008). Supply chain management in the US and Taiwan: An empirical study. Omega: The International Journal of Management Science, 36, 665 - 679, $\underline{\text { CrossRef }}$

- Chandra, C., \& Kumar, S. (2000). An application of a system analysis methodology to manage logistics in a textile supply chain. Supply Chain Management: An International Journal, 5(5), 234-244, CrossRef

- Chen, G., \&Harlock, S.C. (1999). A computer simulation based scheduler for woven fabric production. Textile Res. J., 69(6), $431-439$, CrossRef

- Christopher, M. (2000). The Agile Supply Chain: Competing in Volatile Markets. Industrial Marketing Management, 29(1), $37-44$, CrossRef

- Christopher, M. (2011). Logistics \& Supply Chain Management. Pearson Education Limited, Fourth edition.

- Christopher, M., \& Lee, H. (2004). Mitigating supply chain risk through improved confidence. International Journal of Physical Distribution \& Logistics Management, 34(5), 388 - 396, CrossRef

- Christopher, M., Lowson, R., \& Peck, H. (2004). Creating agile supply chains in the fashion industry. International Journal of Retail \& Distribution Management, 32(8), 367 - 376, CrossRef

- Christopher, M., \&Ryals, L. J. (2014), The Supply Chain Becomes the Demand Chain, Journal Of Business Logistics, Vol.35, No.1, pp.29-35, CrossRef

- Christerson, B., \&Appelbaum, R.P. (1995). Global and local subcontracting: Space, ethnicity, and the organization of apparel production. World Development, 23(8), 1363-1374, CrossRef

- de Brito, M.P., Carbone, V., \&Blanquart, C.M. (2008). Towards a sustainable fashion retail supply chain in Europe: Organisation and performance. Int. J. Production Economics, 114, $534-553$, CrossRef

- de Treville, S., Shapiro, R.D., \&Hameri, A-P. (2004). From supply chain to demand chain: the role of lead time reduction in improving demand chain performance. Journal of Operations Management. 21, 613-627, CrossRef

- Esper, T.L., Ellinger, A.E., Stank, T.P., Flint, D.J., \& Moon, M. (2010). Demand and supply integration: a conceptual framework of value creation through knowledge management. J. of the Acad. Mark. Sci., 38, 5-18, CrossRef

- Gereffi, G. (1999). International trade and industrial upgrading in the apparel commodity chain. Journal of International Economics 48, 37-70, $\underline{\text { CrossRef }}$

- Gillham, F.E.M., Bell, T.M., Arin, T., Matthews, G.A., Le Rumeur, C., \& Hearn, A.B. (1995). Cotton production prospects for the next decade. World Bank technical paper no. WTP 287. Washington, D.C.: The World Bank.

- Heikkilä, J. (2002). From supply to demand chain management: efficiency and customer satisfaction. Journal of Operations Management, 20, 747-767. CrossRef

- Hilletofth, P. (2011). Demand-supply chain management: industrial survival recipe for new decade. Industrial Management \& Data Systems, 111(2), 184-211, $\underline{\text { CrossRef }}$

- Hilletofth, P., Ericsson, D., \& Christopher, M. (2009). Demand chain management: a Swedish industrial case study. Industrial Management \& Data Systems, 109(9), 1179-1196, CrossRef

- Holmström, J., Louhiluoto, P., Vasara, A., \&Hoover, W. E. (2001). The other end of the supply chain. Paper presented at the Supply Chain Forum: an International Journal, 2(2).

- Hwarng, H.B. \&Xie, N. (2008), Understanding supply chain dynamics: A chaos perspective, European Journal of Operational Research, Vol. 184, Iss. 3, pp. 1163-1178, CrossRef

- Inditex (2015). Retrived from www.inditex.com/en/brands/zara. 
- Jacobs, D. (2006). The promise of demand chain management in fashion. Journal of Fashion Marketing and Management: An International Journal, 10(1), 84 - 96, CrossRef

- Jin, B. (2006). Performance implications of information technology implementation in an apparel supply chain. Supply Chain Management: An International Journal, 11(4), 309 - 316, CrossRef

- Kincade, D.H., Regan, C. \& Gibson, F.Y. (2007), Concurrent engineering for product development in mass customization for the apparel industry, International Journal of Operations \& Production Management, Vol. 27, Iss 6, pp. $627-649$, CrossRef

- Kumar, C.C.S. (2001). Enterprise architectural framework for supply-chain integration. Industrial Management \& Data Systems, 101(6), 290 - 304, CrossRef

- Lau, K. H. (2012). Demand management in downstream wholesale and retail distribution: a case study. Supply Chain Management: An International Journal, 17(6), 638-654, CrossRef

- Lee, Y., \&Kincade, D.H. (2003). US apparel manufacturers' company characteristic differences based on SCM activities. Journal of Fashion Marketing and Management: An International Journal, 7(1), 31- 48, CrossRef

- Levi Strauss \& Co. heritage timeline 2 (2014). Retrived from http://www.levistrauss.com/our-story/heritagetimeline.

- Madhani, P. M. (2015), Demand chain management: Enhancing customer lifetime value through integration of marketing and supply chain management, IUP Journal of Business Strategy, Vol.12, No.3, pp. 7-26

- MacCarthy, B.L., \&Jayarathne, P.G.S.A. (2013). Supply network structures in the international clothing industry: differences across retailer types. International Journal of Operations \& Production Management, 33(7), $858-886$, CrossRef

- Masson, R., Iosif, L., MacKerron, G. and Fernie, J. (2007), Managing complexity in agile global fashion industry supply chains, The International Journal of Logistics Management, Vol. 18, Iss 2 pp. 238 - 254, CrossRef

- Perry, P. \&Kyriakaki, M. (2014), The decision-making process of luxury fashion retail buyers in Greece, Journal of Fashion Marketing and Management, Vol. 18, Iss 1, pp. 85 - 106, CrossRef

- Rainbird, M. (2004). Demand and supply chains: the value catalyst. International Journal of Physical Distribution \& Logistics Management, Vol. 34, Iss. 3/4,pp. 230 - 250, CrossRef

- Runfola, A. \&Guercini, S. (2013), Fast fashion companies coping with internationalization: driving the change or changing the model?, Journal of Fashion Marketing and Management: An International Journal, Vol. 17, Iss 2, pp. $190-205$, CrossRef

- Sen, A. (2008). The US fashion industry: A supply chain review. Int. J. Production Economics, 114, 571-593. CrossRef

- Seuring, S. (2004). Integrated chain management and supply chain management comparative analysis and illustrative cases. Journal of Cleaner Production, 12, 1059 - 1071, CrossRef

- Shelton, R.K. and Wachter, K. (2005), Effects of global sourcing on textiles and apparel", Journal of Fashion Marketing and Management: An International Journal, Vol. 9, Iss 3, pp. 318 - 329, CrossRef

- Tokatli, N. (2008). Global sourcing: insights from the global clothing industry-the case of Zara, a fast fashion retailer. Journal of Economic Geography, 8, $21-38$, CrossRef

- U.S. Congress, Office of Technology Assessment (1987). The U.S. Textile and Apparel Industry: A Revolution in Progress-Special Report. OTA-TET-332 (Washington, DC: U.S. Government Printing Office).

- Vrontis, D., \&Vronti, P. (2004). Levi Strauss: an international marketing investigation. Journal of Fashion Marketing and Management: An International Journal, 8(4), 389 - 398, CrossRef 